\title{
Haemodynamic effects of disopyramide in patients after open-heart surgery
}

\author{
N. NAQVI, D. S. THOMPSON, W. E. MORGAN, B. T. WILLIAMS, AND \\ D. J. COLTART
}

From the Departments of Cardiology and Cardiothoracic Surgery, St. Thomas's Hospital, London

SUMMARY Disopyramide phosphate was administered intravenously in a dose of $1.2 \mathrm{mg} / \mathrm{kg}$ body weight over one minute to nine patients after open-heart surgery and coronary artery bypass grafting. The haemodynamic changes were studied during and for 30 minutes after drug administration. Heart rate was unchanged throughout the study. During infusion the only significant changes were an increase in systemic blood pressure and systolic impedance signifying a direct increase in peripheral arterial resistance. Systemic blood pressure remained significantly higher for 10 minutes and systolic impedance for 30 minutes. Immediately after infusion max. dPower/dT, a measure of ventricular contractility, was significantly depressed for 15 minutes. Both cardiac output and aortic flow were significantly depressed for 30 minutes. DPTI/TTI, an estimate of subendocardial supply/demand ratio, showed an insignificant increase throughout the study.

This study shows that intravenous disopyramide starts acting within 45 seconds of the start of infusion, directly increases peripheral arterial resistance, has a brief negative inotropic action, and does not reduce subendocardial blood flow.

Disopyramide (4 diisopropylamino-2-phenyl-2-(2pyridyl) butyramide) has proved to be an effective new antiarrhythmic drug. Its efficacy in suppressing ventricular arrhythmias (Vismara et al., 1974; Mizgala and Huvelle, 1976; Deano et al., 1977) and, to a lesser extent, supraventricular arrhythmias (Lerch, 1976; Daly and Owens, 1977; Ward et al., 1977) is well documented. Electrophysiological studies have shown a beneficial effect in WolffParkinson-White syndrome (Spurrell et al., 1975; Camm and Spurrell, 1977). It has been shown to be effective in the prophylaxis and treatment of arrhythmias occurring after myocardial infarction (Hillis et al., 1976; Jennings et al., 1976).

The haemodynamic effects of disopyramide phosphate (Norpace:Searle) given intravenously to nine patients after open-heart surgery and coronary artery bypass grafting are reported. The particular aims of the study were to measure the time of onset of action of disopyramide and the early haemodynamic changes after intravenous injection.

\section{Subjects and methods}

Nine patients with ischaemic heart disease under-

Received for publication 21 May 1979 going coronary artery bypass grafting were recruited to the study. Prior informed consent was obtained.

Exclusion criteria included the following:

(1) Patients who had received digitalis glycosides within two weeks before the study.

(2) Patients who had received inotropic agents in the 30 minutes before the study.

(3) Patients receiving any other antiarrhythmic agent.

(4) Patients suffering from urinary retention (Large and Todd, 1977) or glaucoma (Trope and Hind, 1978).

(5) Patients with renal failure (Whiting and Elliott, 1977; Whiting and Miller, 1977).

(6) Patients receiving any anticholinergic drug.

(7) Patients with atrioventricular or severe intraventricular conduction defects (Niarchos, 1976; Croxson and Atkin, 1977).

(8) Patients with congestive cardiac failure.

(9) Patients who had a known sensitivity to disopyramide phosphate.

Before closure of the chest after the placement of the bypass grafts a rigid non-cannulating extractable electromagnetic blood flow probe (Carolina Medical Electronics 900 series) with suitable internal circumference was applied to the ascending aorta as previously described (Williams et al., 1972; 
Farnsworth et al., 1977). Details of the use of such a flow probe to assess myocardial performance in man are published elsewhere (Lewis et al., 1978). The connections of the flow probe, and the monitoring equipment used in the study are detailed by Malcolm et al. (1977). It is pertinent to describe these briefly here. The flow probe was connected to a single channel patient isolated flow meter (Carolina Medical Electronics, 'Cliniflow' Model $601 \mathrm{D})$. Arterial pressure was monitored by a micromanometer (Millar Instruments, 'Mikro-Tip' Model 3EA/a) connected on to a three-way tap on a 16 or 18 gauge cannula placed either in the femoral or radial artery. Left atrial pressure was monitored via a fluid filled line which is routinely inserted through the posterior aspect of the left atrium at the end of operations involving cardiopulmonary bypass. The electrocardiogram was taken from an auxiliary socket on the electrocardiographic monitor normally used at the bedside. Pressure and flow signals and the electrocardiogram were displayed on a multichannel oscilloscope (Cardiac Recorders, eight channel, with Type 99 control unit) and recorded on magnetic tape with a sevenchannel recorder (Philips 'Analog-7'). The oscilloscope tape recorder and the flow meter are mounted on a mobile trolley which has been described elsewhere (Bourne and Williams, 1975). Left atrial mean pressure was recorded verbally on the audio channel of the tape recorder at each point in the study so that it was subsequently available when data processing was done. Data stored on magnetic tape was processed 'off-line' using an analogue-todigital converter interfaced with a Varian $620 \mathrm{~L} / 100$ digital computer. The output from the computer is provided in the form of teletype printing (for numerical data), hard copy prints of cathode ray tube displays (of waveforms, pressure volume plots, and associated numerical data), and paper tape (for numerical data, later to be used for statistical processing). $U p$ to 18 seconds of data for each reading were transferred from tape to computer for analysis.

The following values for every heart beat during the 18 second sampling period were analysed:

Heart rate (beats per minute); duration of systole (seconds); stroke volume (ml); maximum pressure $(\mathrm{mmHg})$; minimum pressure $(\mathrm{mmHg})$; mean pressure ( $\mathrm{mmHg}$ ); maximum flow (litres/min); maximum rate of change of flow with respect to time, designated 'max. $\mathrm{dF} / \mathrm{dt}$ '; percentage of stroke volume ejected during systole up to the time of maximum aortic flow, designated ' $\%$ flow to max. flow'; percentage of stroke volume ejected during the first third of systole, designated ' $\%$ flow to $33.3 \%$ syst.'; mean systolic impedance (Newtons/ metre $^{5}$ per $\mathrm{s}$ ) calculated as mean pressure during systole/mean flow during systole; impedance at maximum flow (Newtons/metre ${ }^{5}$ per $s$ ) calculated as pressure at time of maximum flow/flow at time of maximum flow; stroke work (joules/beat) calculated as the time integral during systole of the product of developed pressure and flow; maximum left ventricular ejection power (Watts) calculated as the maximum value of the instantaneous product of pressure and flow; mean left ventricular ejection power; maximum rate of change of ejection power with respect to time, designated ' $m a x$ dPower/dT' (Watts/s); cardiac output (litres/min); diastolic reverse flow (percentage of stroke volume); percentage of stroke volume ejected up to the time of maximum rate of change of flow, designated ' $\%$ flow to max. acceleration'; ratio of diastolic pressure time index/systolic tension time index, designated 'DPTI/TTI'.

Patients were studied when they had been in the intensive care unit for eight to 12 hours after openheart surgery and all values of cardiovascular function were stable and satisfactory. No other medication was given for at least half an hour before and during the study. $10 \mathrm{ml}$ venous blood were withdrawn into a heparinised tube for pretreatment

Table Clinical details of patients studied

\begin{tabular}{|c|c|c|c|c|c|c|c|c|}
\hline \multirow[t]{2}{*}{ Case no. } & \multirow{2}{*}{$\begin{array}{l}\text { Age } \\
(y)\end{array}$} & \multirow[t]{2}{*}{$\operatorname{Sex}$} & \multirow[t]{2}{*}{$W_{t}(\mathrm{~kg})$} & \multicolumn{5}{|c|}{ Cardiac catheterisation data } \\
\hline & & & & $\begin{array}{l}\text { Cardiac index } \\
\left(\mathrm{ml} / \mathrm{min} \text { per } \mathrm{m}^{2}\right)\end{array}$ & $\begin{array}{l}L V E D P \\
(m m H g)\end{array}$ & $\begin{array}{l}\text { LVEDV } \\
\left(\mathrm{ml} / \mathrm{m}^{2}\right)\end{array}$ & $E F$ & Coronary artery disease \\
\hline $\begin{array}{l}1 \\
2 \\
3 \\
4 \\
5 \\
6 \\
7 \\
8 \\
9\end{array}$ & $\begin{array}{l}56 \\
56 \\
62 \\
58 \\
25 \\
39 \\
53 \\
60 \\
47\end{array}$ & $\begin{array}{l}\mathrm{M} \\
\mathbf{M} \\
\mathbf{M} \\
\mathrm{M} \\
\mathbf{M} \\
\mathbf{M} \\
\mathbf{M} \\
\mathbf{M}\end{array}$ & $\begin{array}{l}87 \\
75 \\
83 \\
94 \\
66 \\
75 \\
75 \\
82 \\
83\end{array}$ & $\begin{array}{l}3 \cdot 5 \\
2 \cdot 3 \\
2 \cdot 3 \\
2 \cdot 7 \\
3 \cdot 4 \\
2 \cdot 4 \\
2 \cdot 5 \\
3 \cdot 0 \\
3 \cdot 3\end{array}$ & $\begin{array}{l}7 \\
4 \\
5 \\
8 \\
9 \\
8 \\
5 \\
4 \\
5\end{array}$ & $\begin{array}{l}89 \\
78 \\
64 \\
60 \\
85 \\
84 \\
86 \\
61 \\
58\end{array}$ & $\begin{array}{l}0.76 \\
0.51 \\
0.64 \\
0.55 \\
0.85 \\
0.75 \\
0.76 \\
0.57 \\
0.76\end{array}$ & $\begin{array}{l}\text { Triple vessel } \\
\text { RCA } \\
\text { Triple vessel } \\
\text { LAD circumflex } \\
\text { Triple vessel } \\
\text { LAD } \\
\text { LAD RCA } \\
\text { Triple vessel } \\
\text { LAD circumflex }\end{array}$ \\
\hline
\end{tabular}

LVEDP, left ventricular end-diastolic pressure; LVEDV, lef t ventricular end-diastolic volume; EF, ejection fraction; LAD, left anterior descending artery; RCA, right coronary artery. 


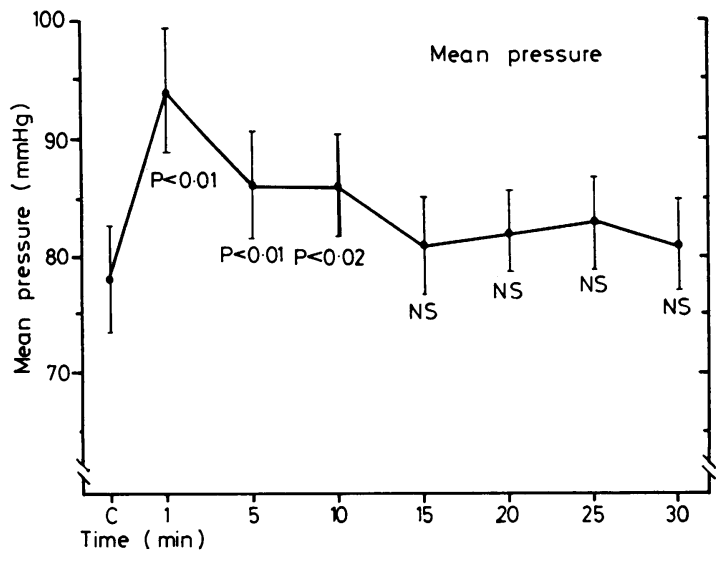

Fig. 1 Changes in mean pressure ( $\pm S E M)$ after disopyramide. $C$, control; $N S$, not significant; SEM, standard error of mean.

drug assay. Three to five control readings were taken, each at five-minute intervals. If the control readings were comparable, disopyramide phosphate (Norpace:Searle) was given intravenously in a dose of $1.2 \mathrm{mg} / \mathrm{kg}$ body weight over a period of one minute. Readings were started at the beginning of the infusion and continued throughout the infusion to enable the time of onset of action of the drug to be measured. Thereafter readings were taken at one-minute intervals for 10 minutes and then at five-minute intervals for the next 20 minutes. $10 \mathrm{ml}$ venous blood were withdrawn for drug assay at five, 10,15, 20, and 30 minutes into heparinised tubes. These samples were centrifuged within a few minutes of collection and the plasma stored at $-20^{\circ} \mathrm{C}$ for subsequent drug assay.

Student's $t$ test for paired samples was used to determine the significance of changes from preinfusion values, each patient acting as his own control. Values are expressed as mean \pm standard error of the mean, and a $P$ value $<0.05$ is considered significant.

The clinical details of the patients studied are given in the Table.

\section{Results}

There was no significant change in heart rate or duration of systole. The mean heart rate at one minute had increased by 4.9 per cent but this was not statistically significant. Thereafter there was no change in heart rate. At 30 minutes the mean heart rate had decreased by an insignificant 1.8 per cent.

The changes in mean blood pressure are shown in Fig. 1. There was an increase in systolic, diastolic, and mean readings which was greatest at one

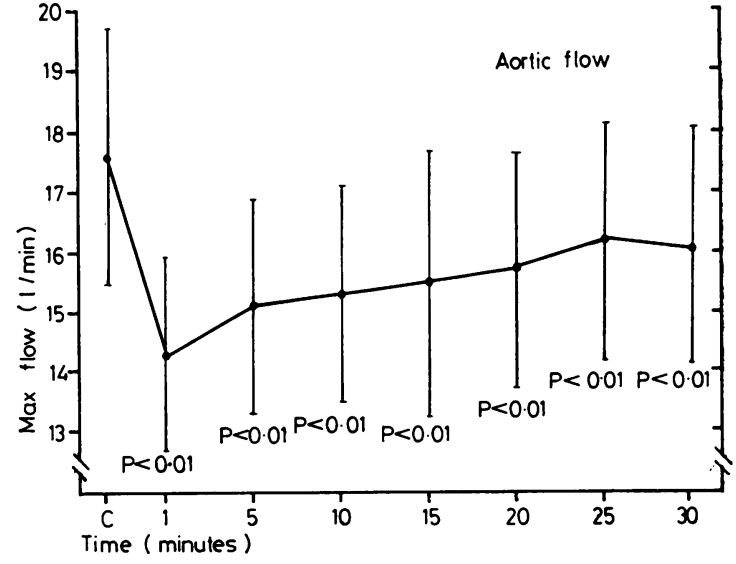

Fig. 2 Changes in maximum aortic flow $( \pm S E M)$ after disopyramide. C, control, SEM, standard error of mean.

minute after the onset of infusion. At five minutes the increase was much less and was not significant for the systolic pressure. The increase in diastolic and mean pressure remained highly significant for up to 10 minutes. The percentage increase in the systolic, mean, and diastolic pressures at one minute were 16,22 , and 28 , respectively. After 10 minutes the increase in mean pressure was not statistically significant. The immediate rise in pressures was followed by an initial rapid and then gradual fall towards control values though the latter were not reached even at 30 minutes. The mean pressure at 30 minutes was 5.2 per cent greater than control values.

Changes in maximum flow are recorded in Fig. 2.

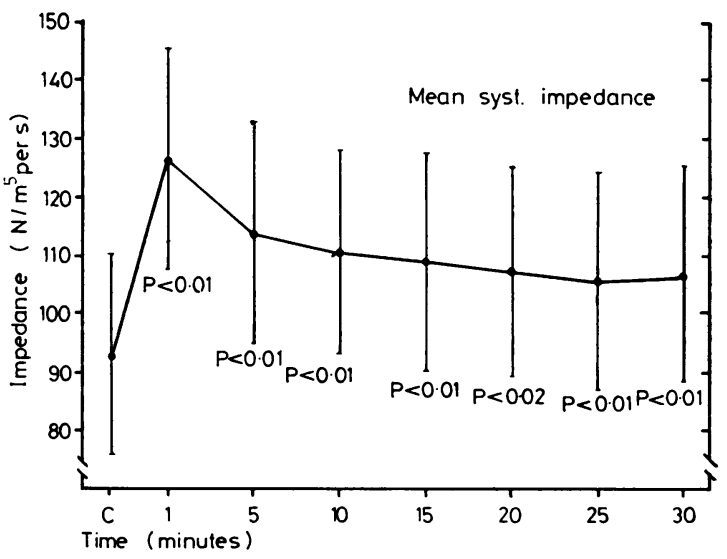

Fig. 3 Changes in mean systolic impedance ( $\pm S E M$ ) after disopyramide. $C$, control; SEM, standard error of mean. 


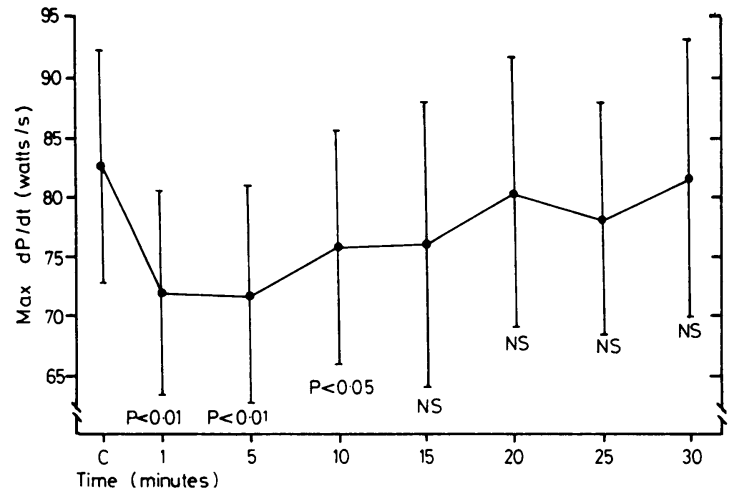

Fig. 4 Changes in max. dPower/dT $( \pm S E M)$ after disopyramide. $C$, control; $N S$, not significant; $S E M$, standard error of mean.

Maximum flow remained significantly depressed throughout the 30 minutes of the study. The maximum depression was at one minute, a mean decrease of 18.8 per cent as compared with control values, but even at 30 minutes maximum flow was still 8.5 per cent less than control values. Per cent flow to max. flow and per cent flow to max. acceleration did not show any significant change. Though diastolic reverse flow lessened, this did not reach statistical significance. Max. $\mathrm{dF} / \mathrm{dT}$ remained significantly depressed compared with control values throughout the study.

Mean systolic impedance, shown in Fig. 3, increased strikingly and this increase remained statistically significant throughout the study, the maximum increase occurring at one minute after the onset of drug infusion and the mean increase being of the magnitude of 35 per cent compared with control values. Again a gradual drift towards control values occurred, but at 30 minutes was still increased

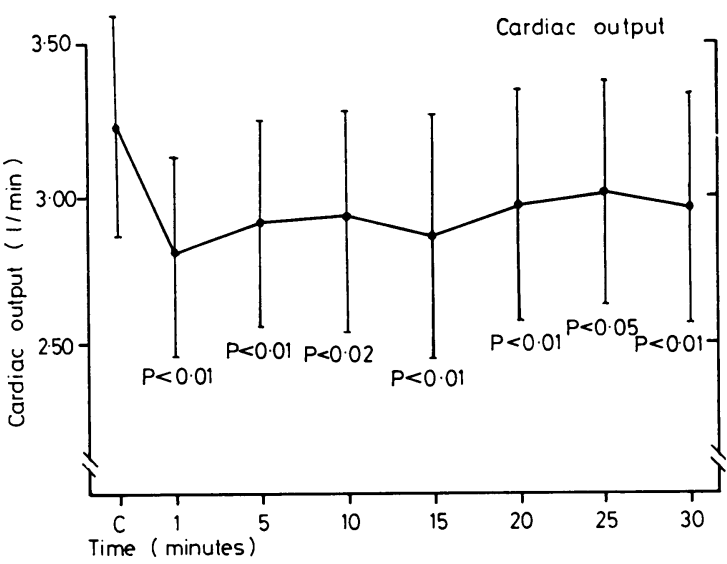

Fig. 5 Changes in cardiac output ( $\pm S E M)$ after disopyramide. $C$, control; SEM, standard error of mean.

by 14.5 per cent. Impedance at maximum flow remained significantly raised throughout the study after the drug infusion.

Max. dPower/dT, a measure of ventricular contractility (Stein and Sabbah, 1976), was initially depressed after drug infusion but by 30 minutes had returned almost completely to control values (Fig. 4). The difference was not statistically significant after 15 minutes. The percentage change from control values was $12,13.5,8.4,8.4$ at one, five, 10 , and 15 minutes, respectively.

Cardiac output was reduced after drug infusion (Fig. 5). This reduction was greatest $(13.3 \%)$ at one minute and remained significantly depressed for 30 minutes. By 30 minutes the mean depression was 8.6 per cent. As expected, changes in stroke volume merely reflected the changes in cardiac output since there was no significant change in heart rate.

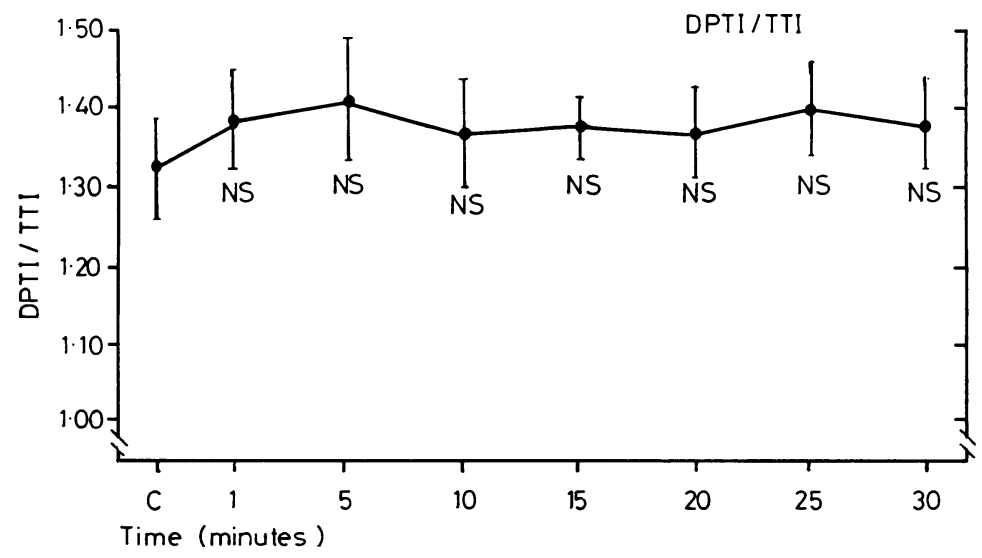

Fig. 6 Changes in DPTI/TTI ( \pm SEM) after disopyramide. $C$, control; NS, not significant; $S E M$, standard error of mean. 


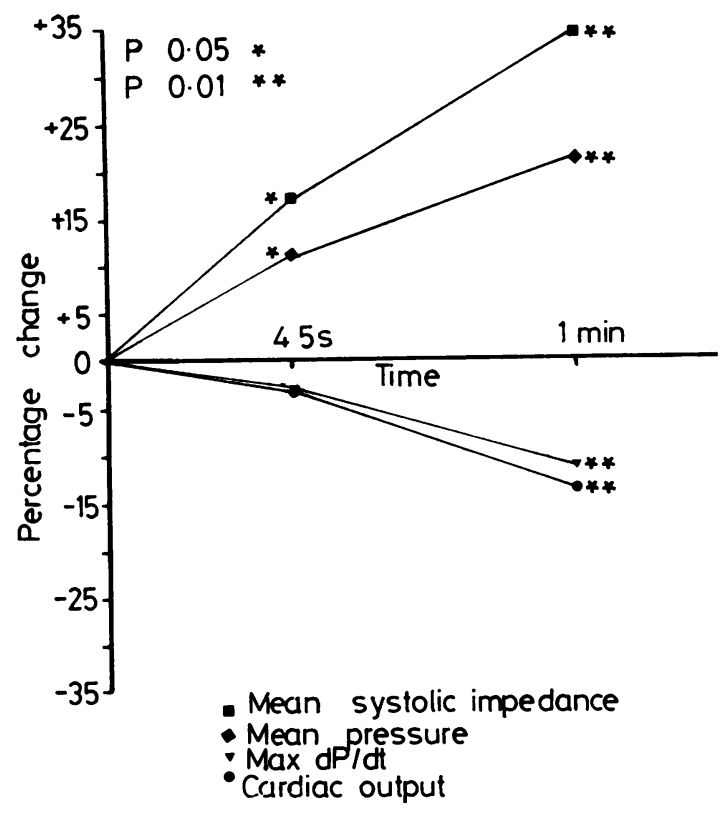

Fig. 7 Changes during and immediately after disopyramide infusion. See text for details.

Although maximum LV ejection power showed an initial depression after drug infusion, this was not statistically significant. The changes in mean LV ejection power were inconstant and were not statistically significant. There was no statistically significant change in stroke work.

The ratio DPTI/TTI, which is an estimate of subendocardial supply/demand relation (Buckberg et al., 1972; Hoffman and Buckberg, 1978), is shown in Fig. 6. At one minute after the start of

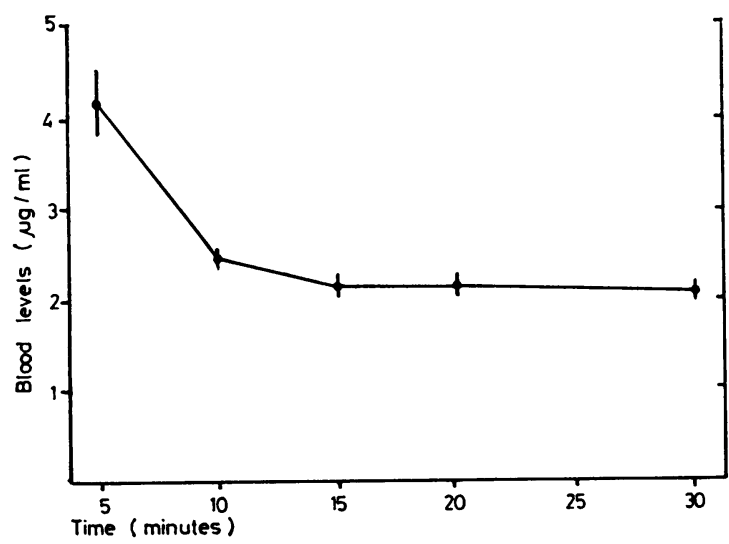

Fig. 8 Blood levels ( $\pm S E M)$ of disopyramide. SEM, standard error of mean. drug infusion there was a 4.5 per cent increase but this was not statistically significant. Thereafter the increase remained steady at around 4 per cent.

Changes occurring during drug administration were monitored in seven patients. There was no significant change in any of the values during the first 30 seconds. The changes that occurred between 30 and 50 seconds after the start of drug infusion are shown in Fig. 7. The increase in mean pressure and mean systolic impedance was significant $(\mathrm{P}<0.05)$, the percentage change being 10.3 and 17 , respectively. There was no significant change in cardiac output and max. dPower/dT at this time.

There was no change in left atrial or right atrial pressure at any stage after drug administration.

The blood levels of disopyramide, determined by the method of Hutsell and Stachelski (1975), are given in Fig. 8.

\section{Discussion}

Before discussing the haemodynamic effects of disopyramide certain facts need to be clarified. We believe, like Slogoff et al. (1977), that continued treatment with beta-blocking drugs before openheart surgery is beneficial and hence continue betablockade until the time of surgery. Some negative inotropic effect from these drugs will inevitably be present for some time during the postoperative period. Jenkins et al. (1973) have claimed that it is possible that the period of cardiopulmonary bypass is a further contributory factor to myocardial depression immediately after surgery regardless of previous cardiac pathology, and in the majority of patients studied by them the ventricular function curves were relatively flat. Hence, in our patients some depression of myocardial function may well have been present before disopyramide was administered. However, our study is particularly relevant since this is just the situation in which disopyramide is often used, that is after open-heart surgery, after myocardial infarction complicated by arrhythmias, etc.-situations where myocardial depression is often an important factor.

The other point to be noted is that the dose of disopyramide used in this study was fairly modest. However, the plasma levels of the drug were within the accepted therapeutically effective range which is between 2 and $4 \mu \mathrm{g} / \mathrm{ml}$ (Karim, 1975; Rangno et al., 1976). The fact that the drug was given over one minute and not longer could well have contributed to the extent of the changes seen at the one-minute period.

In animal experiments disopyramide has been shown to have a weak negative inotropic effect (Mokler and Van Arman, 1962; Mathur, 1972; 
Nayler, 1976). Baines et al. (1976) using beagle dogs found that intravenous disopyramide reduced cardiac output by 9 to 22 per cent, depressed cardiac contractility, reduced coronary flow, and produced only small inconstant changes in heart rate.

Changes in systemic blood pressure after disopyramide administration have varied in different series. The variability is probably attributable to differences in left ventricular function of the patients studied. A fall in blood pressure was found by Jensen et al. (1975) in patients who had imminent or manifest heart failure, and by Sutton (1976) in patients with abnormal left ventricular function. Hulting and Rosenhamer (1975) found no significant change in mean arterial pressure measured five and 10 minutes after drug administration, but from the twentieth minute to the end of the observation period (180 minutes) mean arterial pressure was significantly increased above control values. Befeler (1975) and Marrot et al. (1976) have reported a rise in blood pressure after disopyramide administration. We found an immediate rise in systolic, diastolic, and mean pressure which was maximal at one minute, and these pressures, though returning towards control values, remained raised throughout the study. At five minutes the rise in blood pressure was only marginally more than that in Marrot et al.'s study (1976)7,14 , and 11.7 per cent compared with 7,10 , and 7 per cent in systolic, diastolic, and mean blood pressures, respectively. Initially it was thought that the increase in blood pressure was a reflex response to the lowering of cardiac output (Befeler, 1975). However, during infusion of the drug there was a significant rise in mean pressure and mean systolic impedance (Fig. 7). There was no decrease in rate of change of power and the change in cardiac output was not significant. Hence the significant early change in systemic pressure and systolic impedance but not in cardiac output and max. dPower/dT suggested that the increase in blood pressure was not a reflex response to lowering of cardiac output but occurred independently and presumably was a result of increased peripheral vascular resistance. Vismara et al. (1975) have shown that disopyramide directly increased vascular resistance. As expected, increase in afterload raised the peak ventricular and aortic pressure and decreased the peak flow (Milnor, 1975).

Most haemodynamic studies agree that disopyramide is a negative inotropic agent (Jensen et al., 1975; Hulting and Rosenhamer, 1975; Marrot et al., 1976). This was confirmed in our study where max. dPower/dT was reduced by 12 per cent and cardiac output by 13.3 per cent at one minute after the onset of infusion of the drug. Though cardiac output alone may be depressed by increases in afterload, max. dPower/dT is not, being independant of afterload (Stein and Sabbah, 1976), confirming that disopyramide has a negative inotropic action. Significant depression of max. dPower/dT was shortlived and the reduction in cardiac output was less than 10 per cent after 15 minutes. Hence the negative inotropic action of disopyramide is transient, and progressively diminishes in intensity.

In most studies there has been no significant change in heart rate in patients in sinus rhythm (Jensen et al., 1975; Hillis et al., 1976; Marrot et al., 1976). This was found in our study as well. Since disopyramide is known to have weak anticholinergic properties (Baines et al., 1976; McHaffie et al., 1977) some increase in heart rate might be expected. However, the early increase in systolic impedance and systemic blood pressure would reflexly slow the heart. It is possible that this, perhaps coupled with the membrane stabilising effect of the drug (Reid and Williams, 1977), would oppose the vagolytic effect and result in no change in heart rate.

Finally, our results of DPTI/TTI show that there is no deterioration in subendocardial blood flow after disopyramide administration. At all times after disopyramide there was an increase in the ratio, varying from 3 to 6 per cent, though this was not statistically significant. This is of considerable benefit when disopyramide is given to patients with anaemia, aortic valve disease, coronary atherosclerosis, acute myocardial infarction, or after cardiac surgery. All these conditions are known to be associated with impairment of blood supply to the subendocardial region (Hoffman and Buckberg, 1975). We wish to point out that in our study the ratio DPTI/TTI has been derived by assuming that recorded peripheral arterial pressure waveform during systole is identical in pressure values at every instant with the pressure waveform in the aorta and left ventricle, and that the mean left atrial pressure is a valid approximation to left ventricular enddiastolic pressure.

We have thus shown that disopyramide has a brief negative inotropic action, that it increases peripheral arterial resistance for at least 30 minutes, and that it does not reduce subendocardial blood flow. The onset of action of the drug is within 45 seconds of the start of intravenous infusion.

We gratefully acknowledge the assistance of Searle Laboratories and Miss Margaret Stratford. The computer programme used in this study was written by $\mathrm{Mr}$ Martin Stoate of the Bioengineering Department of St. Thomas's Hospital. Dr N. Naqvi was supported by the Kleinwort Research Fund. 


\section{References}

Baines, M. W., Davies, J. E., Kellett, D. N., and Munt, P. L. (1976). Some pharmacological effects of disopyramide and a metabolite. Fournal of International Medical Research, 4, Suppl. 1, 5-7.

Befeler, B. (1975). The hemodynamic effects of Norpace (Part 1). Angiology, 26, Suppl. to January, 99-101.

Bourne, P. R., and Williams, B. T. (1975). A cardiac monitor combining flow and pressure measurement. Biomedical Engineering, 10, 453-455.

Buckberg, G. D., Fixler, D. E., Archie, J. P., and Hoffman, J. I. E. (1972). Experimental subendocardial ischaemia in dogs with normal coronary arteries. Circulation Research, 30, 67-81.

Camm, J., and Spurrell, R. A. J. (1977). An electrophysiological assessment of the effect of intravenous disopyramide in the Wolff-Parkinson-White syndrome. In Proceedings of Disopyramide (Rythmodan) Seminar, St. Fohn's College, Cambridge, 24-25 March 1977, pp. 41-47, Viking Press, New York.

Croxson, R. S., and Atkin, W. S. (1977). A multicentre study of intravenous disopyramide in arrhythmias complicating myocardial infarction. Fournal of the Irish Medical Association, 70, Suppl. to 14, 10-12.

Daly, K. M., and Owens, A. (1977). Intravenous disopyramide in acute termination of cardiac arrhythmias. Fournal of the Irish Medical Association, 70, Suppl. to $14,7-9$.

Deano, A. D., Wu, D., Mautner, R. K., Sherman, R. H., Ehsani, A. E., and Rosen, K. M. (1977). The antiarrhythmic efficacy of intravenous therapy with disopyramide phosphate. Chest, 71, 597-606.

Farnsworth, A. E., Angerpointer, T. A., Lewis, G. J. R., Bourne, P. R., and Williams, B. T. (1977). A monitor for the continuous assessment of left ventricular performance after open-heart operations. Annals of Thoracic Surgery, 23, 169-172.

Hillis, W. S., Tweddel, A., Lorimer, A. R., and Lawrie, T. D. V. (1976). Some aspects of the clinical pharmacology of intravenous disopyramide after myocardial infarction. Fournal of International Medical Research, 4, Suppl. 1, 74-77.

Hoffman, J. I. E., and Buckberg, G. D. (1975). Pathophysiology of subendocardial ischaemia. British Medical fournal, 1, 76-79.

Hoffman, J. I. E., and Buckberg, G. D. (1978). The myocardial supply/demand radio-a critical review. American fournal of Cardiology, 41, 327-332.

Hulting, J., and Rosenhamer, G. (1975). Haemodynamic and electrocardiographic effects of disopyramide in patients with ventricular arrhythmia. Acta Medica Scandinavica, 199, 41-51.

Hutsell, T. C., and Stachelski, S. J. (1975). Determination of disopyramide and its mono- $\mathrm{N}$-dealkylated metabolite in blood serum and urine. Fournal of Chromatography, 106, 151-158.

Jenkins, B. S., Branthwaite, M. A., and Bradley, R. D. (1973). Cardiac function after open-heart surgery. Relation between the performances of the two sides of the heart. Cardiovascular Research, 7, 297-305.

Jennings, G., Jones, M. B. S., Besterman, E. M. M.,
Model, D. G., Turner, P. P., and Kidner, P. H. (1976). Oral disopyramide in prophylaxis of arrhythmias following myocardial infarction. Lancet, 1, 51-54.

Jensen, G., Sigurd, B., and Uhrenholt, A. (1975). Haemodynamic effects of intravenous disopyramide in heart failure. European fournal of Clinical Pharmacology, 8, 167-173.

Karim, A. (1975). The pharmacokinetics of Norpace. Angiology, 26, Suppl 1, 85-98.

Large, S. H., and Todd, C. H. (1977). Disopyramide associated with urinary retention. Lancet, 2, 1362.

Lerch, W. (1976). Bericht über eine kontrollierte Studie zur Wirksamkeit des Präparates B 712 (Disopyramiddihydrogenphosphat) bei absoluter Arrhythmie mit Vorhofflimmern. Therapiewoche, 26, 6515-6522.

Lewis, G. J. R., Poole-Wilson, P. A., Angerpointer, T., Coltart, D. J., and Williams, B. T. (1978). Use of electromagnetic flow probes to assess myocardial performance in man. European Fournal of Cardiology, 7, 283-290.

McHaffie, D. J., Guz, A., and Johnston, A. (1977). Impotence in patient on disopyramide. Lancet, 1, 859.

Malcolm, A. D., Stoate, M. W., Houston, B. D., Williams, B. T., and Webb-Peploe, M. M. (1977). Comprehensive computer-aided cardiocirculatory monitoring after open-heart surgery and application in measurement of the effects of adrenaline. In Computers in Cardiology. Proceedings of the 1977 Conference, ed. H. G. Astrow and K. L. Ripley, pp. 67-77. IEEE Computer Society, Long Beach, California.

Marrot, P. K., Ruttley, M. S. T., Winterbottam, J. T., and Muir, J. R. (1976). A study of the acute electrophysiological and cardiovascular action of disopyramide in man. European fournal of Cardiology, 4, 303312.

Mathur, P. P. (1972). Cardiovascular effects of a newer antiarrhythmic agent, disopyramide phosphate. American Heart fournal, 84, 764-770.

Milnor, R. W. (1975). Arterial impedance as ventricular afterload. Circulation Research, 36, 565-570.

Mizgala, H. F., and Huvelle, P. R. (1976). Acute termination of cardiac arrhythmias with intravenous disopyramide. Fournal of International Medical Research, 4, Suppl. 1, 82-85.

Mokler, C. M., and Van Arman, C. C. (1962). Pharmacology of a new antiarrhythmic agent, gamma-diisopropyl-amino-alpha-phenyl-alpha- (2-pyridyl) butyramide (SC-7031). Fournal of Pharmacology and Experimental Therapeutics, 136, 114-124.

Nayler, W. G. (1976). The pharmacology of disopyramide. Fournal of International Medical Research, 4, Suppl. 1, 8-12.

Niarchos, P. A. (1976). Disopyramide serum levels and arrhythmia conversion. American Heart fournal, 92, 57-64.

Rangno, R. E., Warnica, W., Ogilvie, R. I., Kreeft, J., and Bridger, E. (1976). Correlation of disopyramide pharmacokinetics with efficacy in ventricular tachyarrhythmia. Fournal of International Medical Research, 4, Suppl. 1, 54-58. 
Reid, D. S., and Williams, D. O. (1977). Disopyramide and sinoatrial node function. In Proceedings of Disopyramide (Rythmodan) Seminar, St. Fohn's College, Cambridge, 24-25 March 1977, p. 31. Viking Press, New York.

Slogoff, S., Keats, A. S., Wayne Hibbs, C., Edmonds, C. H., and Bragg, D. A. (1977). Failure of general anaesthesia to potentiate propranolol activity. Anesthesiology, 47, 504-508.

Spurrell, R. A. J., Thorburn, C. W., Camm, J., Sowton, E., and Deuchar, D. C. (1975). Effects of disopyramide on electrophysiological properties of specialised conduction system in man and on accessory atrioventricular pathway in Wolff-Parkinson-White syndrome. British Heart fournal, 37, 861-867.

Stein, P. D., and Sabbah, H. N. (1976). Rate of change of ventricular power: an indication of ventricular performance during ejection. American Heart fournal, 91, 219-227.

Sutton, R. (1976). Haemodynamics of intravenous disopyramide. Fournal of International Medical Research, 4, Suppl. 1, 46-48.

Trope, G. E., and Hind, V. M. D. (1978). Closed angle glaucoma in patient on disopyramide. Lancet, $1,329$.

Vismara, L. A., De Maria, A. N., Miller, R. R., Amsterdam, E. A., and Mason, D. T. (1975). Effects of intravenous disopyramide phosphate on cardiac function and peripheral circulation in ischaemic heart disease (abstract). Clinical Research, 23, 87A.

Vismara, L. A., Mason, D. T., and Amsterdam, E. A. (1974). Disopyramide phosphate. Clinical efficacy of a new oral antiarrhythmic drug. Clinical Pharmacology and Therapeutics, 16, 330-335.

Ward, D. E., Camm, A. J., and Spurrell, R. A. J. (1977). Clinical experience with disopyramide in paroxysmal atrial fibrillation. Fournal of the Irish Medical Association, 70, Suppl. to 14, 13-15.

Whiting, B., and Elliott, H. L. (1977). Disopyramide in renal impairment. Lancet, 2, 1363.

Whiting, B., and Miller, S. (1977). Disopyramide pharmacokinetics relationships to bioavailability and renal impairment. In Proceedings of Disopyramide (Rythmodan) Seminar, St. Fohn's College, Cambridge, 24-25 March 1977, p. 11. Viking Press, New York.

Williams, B. T., Sancho-Fornos, S., Clarke, D. B., Abrams, L. D., Shenk, W. G., jun, and Barefoot, C. A. (1972). The Williams-Barefoot extractable blood flow probe; design, transducer characteristics and clinical applications in cardiac surgery. Fournal of Thoracic and Cardiovascular Surgery, 63, 917-921.

Requests for reprints to Dr D. J. Coltart, Department of Cardiology, St. Thomas's Hospital, London SE1 7EH. 